\title{
An Uncertain Global Environment. Social Extremity, and Sociology of COVID-19
}

\author{
Raffaele Federici* \\ Civil and Environmental Department of Engineering, University of Perugia, Italy \\ *Corresponding author: Raffaele Federici, Civil and Environmental Department of Engineering, University of Perugia, \\ Italy
}

ARTICLE INFO

Received: 幽 March 10, 2020

Published: March 17, 2020

Citation: Raffaele Federici. An Uncertain Global Environment. Social Extremity, and Sociology of COVID-19. Biomed J Sci \& Tech Res 26(4)-2020. BJSTR. MS.ID.004388.

\begin{abstract}
The COVID-19 outbreak is a contradiction of the globalization, one of the most seductive and also one of the most difficult concepts in contemporary social science. A contradiction that will change social behaviour, in many activities. Reflecting sociologically means rethinking how society is able to respond to such a profound crisis, not only in health and economic terms, but how to rethink the idea of a human community.
\end{abstract}

Keywords: Risk; Uncertainty; Society; Communication; COVID-19

\section{Introduction}

\section{An Uncertain Context}

I am writing this short scientific contribution in the midst of a modified social reality following the outbreak of the COVID-19 in Italy. In these days the authorities have decided an absolute lockdown of common and daily activities, from work to entertainment, an episode so exceptional that it calls for some reflections that partly come from the memory and the history that passes and embraces literature, the history of medicine and the most recent acquisitions on the socio-anthropological mechanisms underlying the functioning of contemporary societies. Social reality that suddenly changed its shape: the streets have emptied, the public places are closed, the spring air which instead of promising the good season of light and warmer days, becomes almost oppressively. Uncertainty becomes the skin of social reality. Everything that until yesterday was taken for granted becomes something elusive. A situation that requires a reflection that embraces the sense of the very idea of development of Western civilization. This changeover will not probably last long but the effects will bring tensions in the society since «the social structure today is ruled by an economic principle of rationality, defined in terms of efficiency in the allocation of resources; the culture, in contrast, is prodigal, promiscuous, dominated by an anti rational, anti-intellectual temper» D Bell [1]. This outbreak is also a contradiction. A contradiction that has changed social behaviour, imposing, for example, a social distancing in almost all human activities. From this point of view, reflecting sociologically means rethinking how society is able to respond to such a profound crisis, not only in health and economic terms, but how to rethink the idea of a human community.

The 2019-2020 COVID-19 outbreak in China and in the entire world has been deemed an exceptional situation in the most recent epidemiological history, due to its geographic scope, morbidity and mortality rates, uncertainties relating both to treatments and to the natural reservoir of the virus, and the extent to which it generated global anxieties. In these days when there is a lot of talk about the risk posed by the possibility of contracting the virus and developing respiratory failure, one should reflect on the idea of risk, in a global and increasingly uncertain world. The extension of the global village, therefore, accentuating the permeability of the borders, ensures that every event obeys the law of the domino effect, also involving and influencing culturally distant and geographically realities distant. The world system is complex. It is complex in the sense that it contains phenomena exceeding them adjustment capacity we have and complexity, understood as essential unpre- 
dictability, it is the property of a system of showing possible but not predetermined behaviours and its description implies the passage from a positive rationality to a procedural or instrumental rationality. Within this frame, globalization with its thousand and different tentacles makes, therefore, closer thanks to a path that facilitates the acquisition of new ways of think, feel and relate, but it makes human beings less protected, placing them in scope of threats. In an increasingly complex, articulated, polycentric world made up of new political, social, economic and ethnic-cultural realities such as that of contemporary society, the uncertainty of an existence is projected which appears increasingly less programmable and predictable.

Sociologists exhibits a pluriparadigmatic definitions of risk, all concepts do «presuppose a distinction between predetermination and possibility [...] for if the future were either predetermined or independent of present human activities, the notion of risk makes no sense» Jaeger, et al. [2]. Today, risk is often understood as one of the most important features of contemporary society in the Western world. For Giddens: «To live in the universe of high modernity [is] to live in an environment of chance and risk, the inevitable concomitants of a system geared to the domination of nature and the reflexive making of history» Giddens [3]. The concepts of risk and danger seems to be associated with the development of human life not only in terms of the danger of the environment and the degree of uncertainty present, but also in relation to the risks produced by the intensification of human activity. According to Luhmann: «Normally risk is defined by its antonym safety and by its relation to practical affairs. But this amounts to a paradoxical or at least ambiguous definition because in practical affairs there is absolute safety. The future always contains elements of uncertainty (otherwise it would not be visible as the future, distinguished from the present), and the increasing complexity of perspectives and information may render our knowledge even more uncertain» Luhmann [4]. In an oblique ways, the risk has always pervaded every human activity and in contemporary societies the risks to health and the environment have become priority topics in the public debate and in the media agenda, assuming a significant role in orienting individual choices and compartments and public policies.

Human beings live in what is called a risk society Beck [5] where access to information is considered a right of citizenship, where the ability to face the threats to which human beings are exposed becomes the challenge for the lives of many individuals. According to Beck, the risks of contemporaneity know no geographical boundaries or barriers between social classes, although the poorer classes are generally more vulnerable, and may also have consequences for future generations. The risk assessment processes therefore face a space that is impossible to circumscribe the results of which are difficult to evaluate over time. Beck stressed that these risks are not simply the result of errors and defaults, and therefore cannot be re- duced as undesirable side effects, but, on the contrary, are inherent in the complexity of human activity. As a consequence of human decisions, the risks in this uncertain global world take on a strong political connotation, easily becoming a possible terrain of social and economic-financial conflicts Beck [6].

\section{Communication, Culture, and COVID-19. Exploring the Unknown}

In this context, characterized by growing global uncertainty, scientific dissemination takes on a central role for the correct interpretation of risks in order to avoid misinformation. Furthermore, I remember how in 1982 the socio-cultural theory of risk, proposed by Mary Douglas and Aaron Wildavsky, allowed to show how the attitude towards a danger is influenced by that set of norms, values, belief systems and social behaviours that they constitute the culture and organization of a community Douglas, et al. [7]. An interpretation that allows us to explain how different source judgments exist at a risk. The controversies about risk, therefore, would not only be the result of a distorted perception, but also the result of a social comparison between judgments influenced by moral values and political orientations. According to Douglas and Wildavsky, the understanding of risk depends on the socio-cultural context and can not only be discerned by the results and technical analyzes, and since the risk decisions are also the result of a continuous process of social negotiation, it is not said at all that risks are always accepted as actual. Risk and Culture (1982) begins with the proposition that «total knowledge» would be necessary for us to understand the risks we face. The number of possible dangers is infinite, and «[s]ince no one can attend to everything, some sort of priority must be established among danger» Douglas, et al. [7].

Douglas and Wildavsky reason that «only social consent keeps an issue out of contention, and therefore that the perception of risk is itself a social process» Douglas, et al. [7]. Indeed, precisely the case of Covid-19, coronavirus, could be included within the categorization proposed by Douglas and Wildavsky since at the beginning of the outbreak the acceptability of the risk, on which the precautionary and preventive measures depend, is it was judged on political and social factors so that the evaluative judgment was not based on the actual danger of the virus. Since the Novel Coronavirus (COVID-19) which was first identified in Wuhan, China, in December 2019 among a cluster of patients that presented with an unidentified form of viral pneumonia, there has been a succession of estimates of the risk of world contagion, often underestimated. All this happened because the perception of risk is the result of a cultural interpretation of reality and these factors do not always lead to a correct perception of risks: the location of each society on the global cultural map is objective. People build their judgments through interpretative paths that are certainly distinct from those of the experts, but that not for this they can be labelled as "irrational" since are non-logical in the Pareto view Boudon [8]. However, 
this interpretative framework is the basis of every precaution and prevention system since when a potential risk becomes effective and a disaster occurs, the containment actions are often insufficient. In order to avoid the process of weakening the perception of risk, as in the case of viral epidemics, communication must never be denied but should maintain a level of authoritativeness such as to avoid misunderstandings and unjustified panic. The same precautionary principle (Vorsorgeprinzip) also leans on the need to understand how the sharing of a culture of risk is essential in order to mediate the knowledge that actors acquire on how to relate to dangers and problematic situations, to describe to other actors the causes and dynamics of events, and to provide explanations and justifications for their behaviours.

\section{Social Attitudes, Lockdown and Epidemiology}

Defining and socially coding the attributes of the objects or situations that must be considered possible sources of danger, and establishing the regularity and plausibility of the causal links between the risky events helps in fact to reduce the interpretative uncertainty about the phenomenal reality and avoids the expensive recourse to continuous procedures of interpretative mediation between individuals. Social attitudes towards risks must therefore always be analyzed and evaluated in relation to the social context in which they are developed. An event or activity deemed risky by some social groups may indeed appear to be non-hazardous to other groups that do not have the same belief system, since the decision to comply, accept or reject a risk is largely socially constructed within the group to which an actor refers. In the field of precaution and prevention, the possibilities of science to intervene to modify social attitudes towards risks are therefore lower than those of culture because at the social level it is the common experience and not the measure of risk which establishes which are the most probable risks, more harmful, what their acceptability threshold is and how they should be avoided. In this sense, institutions play a fundamental role in the formation and development of social attitudes towards risk. To rationally communicate the risks associated with the almost pandemic spread of COVID-19 virus it is not enough to use objective data or a rational approach, because the perception of risks is a very complex phenomenon that takes shape based on people's experience and beliefs. This leads to underestimate or overestimate an event and simultaneously triggers reactions that are not proportionate to the phenomenon.

Three months after the emergence of the outbreak of COVID-19 from Hubei province with particularly incisive implications not only in China but also in South Korea, Italy, and Iran some indications seem to emerge and particularly a combination of two key forms of risk. First, there is substantial scientific uncertainty about the cause of the outbreak, including the identity and nature of the pathogen, and thus the likelihood and means of infection. Second, there is a considerable uncertainty about the degree of effective- ness of specific interventions or measures to reduce the likelihood or consequences of infection where lockdown all the activities seems to be the only way out. We now know that COVID-19 actually spread relatively fast, infectivity was largely confined to when individuals were unwell, and infection largely affected adults. This meant that traditional public health measures, such as tracing and isolating cases, were effective public health measures including quarantine. COVID-19 is perhaps the most striking example in contemporary times of the widespread use of traditional, non-medical, public health measures to contain an infectious disease outbreak. These measures can be divided into two categories.

First, those decreasing contact between infectious and susceptible people, such as quarantine, travel restriction and increased social distance. Second, those decreasing effective contact, the likelihood of transmission occurring should contact between infectious and susceptible persons occur, through case and contact hygiene, including washing hands and environmental hygiene, such as disinfection. Interesting here is that, despite the millions spent on public health measures concerning infectious disease, relatively little has been invested in considering the behavioural response to infectious disease outbreaks, and how this affects the epidemiology of disease and its wider, predominantly socio-economic, repercussions. Clearly some of the changes in behaviour that individuals undergo when faced with a communicable disease outbreak, such as reductions in visits to restaurants, cinemas and sports, have both an economic and epidemiological impact. Knowledge of how a certain behaviour change might affect the course of the epidemic, and what its possible economic impact would be, would help decision-makers give appropriate advice. Thus, quantifying the behavioural changes that might be expected in the face of different threats would significantly help improve both epidemiological and socio-economic forecasting.

\section{Lessons to be Learnt. Theoretical Perspectives}

In this complex frame there are several lessons for policy concerning risk that may be learnt from the COVID-19 outbreak and oblige us fundamentally to recast our theoretical understanding of the nature of precaution and prevention about epidemics even in terms of Evidence Based Medicine that should be oriented toward an Evidence Based Ethics Federici [9]. First, a change in attitude from emergency responsiveness to precaution and preventive preparedness is needed, as part of a more complex and strategic approach to planning for infectious disease outbreaks. By definition, emergencies offer a limited timeframe for taking action, and would thus benefit from a clear chain of command, coordination among relevant institutions. Clarity of responsibility, accountability during outbreaks, from local to the global levels, is imperative for effective action. This includes institutions beyond the health sector, such as transportation, communications, finance, water and sanitation, defence, housing and education. Further, when an outbreak occurs, 
decisions need to be taken by a diverse range of actors, from different perspectives and at varying points in the policy making process. Given the nature of public emergencies, in terms of timeframe, potential unknowns and geographic reach, this decision making process can be highly challenging. Yet the effectiveness of the emergency response can ultimately hinge on the quality of decision-making.

Besides, as a part of this decision-making process, there is a need for understanding more fully the costs and benefits of effective responses. Economic data is often focused on direct and immediate costs, such as drugs, other interventions, health care services, to the relevant national health sector. A wider account of social and macroeconomic costs will underpin a more strategic approach to decision making, and contribute to more informed decisions that are taken proactively, rather than reactively, prior to and during emergencies. Furthermore, COVID-19 outbreak demonstrated the importance of a worldwide surveillance and response capacity to address emerging risks through timely reporting, rapid communication and evidence-based action. It will be critical to ensure that interventions respect public health ethics and fundamental human rights. Many of the public health measures used during the COVID-19 outbreak, especially quarantine and regional lockdown may conflict with certain human rights. In order to plan a response to global infectious disease outbreaks it will therefore be important to consider a range of issues concerning the nexus between containment, local culture and human freedoms. In the fullness of time, COVID-19 outbreak emphasised the importance of communications with domestic and international policy makers, financial markets, the travel industry and other key sectors.

There is need for better understanding of the complexity of any risk surrounding viral disease outbreaks. Within this context risk assessment can also be used to improve public communication. An understanding of what drives the perception of risk is therefore sorely needed. In this frame, individuals, institutions, organisations, and communities need to strengthen social capital, which provides the building block for our socio-psychological defence. Social capital is a critical resource for individuals, and society collectively, to solve problems and improve well-being. The social system and the social capital in a community relevant to health consists of at least three elements: physical structure, social structure and social cohesion. A community's physical structure has both direct influences on health through exposure to risks and indirect effects through the creation or neglect of health-inducing environments.
Social structure in a community is reflected in such things as its meeting places, mechanisms for income redistribution and opportunities for exchange and interaction. This, too, has both direct effects on health, ensuring the availability of basic prerequisites for health, and indirect effects, facilitating collective problem solving or collective identity. Finally, social cohesion, which is the result of social capital, is very much the product of the adequacy of physical and social structure in a community. Along with such things as the cultural or social homogeneity of a community the physical and social structure can either encourage or discourage mutual support and caring, self-esteem and a sense of belonging, and enriched social relationships. All of these have been shown, largely by social scientists, to have an influence on the health of a community's member Patrick, et al. [10]. In this difficult task of writing down this uncertain future, defining the principles of a new ethics of responsibility regarding the outcome of a COVID-19 outbreak, and the contribution of sociological theory because we need to explain things in the world also by giving a voice to unheard voices, that may help to support a much needed societal dialogue in adverse times [11].

\section{References}

1. D Bell (1972) The cultural contradictions of capitalism. In Journal of Aesthetic Education 6(1,2): 11-38.

2. C Jaeger, O Renn, EA Rosa, T Webler (2001) Risk, Uncertainty, and Rational Action. Sterling Earthscan Publications, London.

3. A Giddens (1991) Modernity and Self-Identity: Self and Society in the late Modern Age. Stanford: Stanford University Press.

4. N Luhmann (1996) Modern society shocked by its risks. Hong Kong: The Social Science Research Centre, University of Hong Kong.

5. U Beck (1986) Risikogesellschaft - Auf dem Weg in eine andere Moderne. Frankfurt aM: Suhrkamp.

6. U Beck (1991) Politik in der Risikogesellschaft. Frankfurt aM: Suhrkamp.

7. M Douglas, A Wildavsky (1982) Risk and Culture. An Essay on the Selection of Technological and Environmental Dangers. Berkeley and London: University of California Press.

8. R Boudon (2013) Les actions logiques e non logiques selon Pareto. in Revue Européenne des Sciences Sociales 51-52: 19-46.

9. R Federici (2010) Dalla Evidence-Based-Mecine alla Evidence-BasedEthics: il medico e il framacistra fra ricette e cure domestice. In: A Marradi, D Nigris (Eds.)., Salute e Società. Evidence-Based Medicine: una critica XI 1: 154-166.

10. DL Patrick, TM Wickizer (1995) Community and health. In: BC Amick, S Levine, AR Tarlov, CD Walsh (Eds.)., Society and Health, Oxford University Press, New York, USA.

11. Camus (1948) The Plague: A Novel. New York, USA. 
ISSN: 2574-1241

DOI: $10.26717 /$ BJSTR.2020.26.004388

Raffaele Federici. Biomed J Sci \& Tech Res

(C) (P) This work is licensed under Creative Submission Link: https://biomedres.us/submit-manuscript.php

$\begin{array}{ll}\text { BIOMEDICAL } & \text { Assets of Publishing with us } \\ \text { RESEARCHES } & \text { - Global archiving of articles } \\ \text { - Immediate, unrestricted online access } & \text { - Rigorous Peer Review Process } \\ & \text { - Authors Retain Copyrights }\end{array}$

